\begin{tabular}{l} 
Sharif University of Technology \\
Scientia Iranica \\
SCIENTIA \\
IRAN \\
Thansactions A: Civil Engineering \\
\hline
\end{tabular}

\title{
Optimal design of monopile offshore wind turbine structures using CBO, ECBO, and VPS algorithms
}

\author{
A. Kaveh ${ }^{\mathrm{a}, *}$ and S. Sabeti ${ }^{\mathrm{b}}$ \\ a. Centre of Excellence for Fundamental Studies in Structural Engineering, Iran University of Science and Technology, Narmak, \\ Tehran, P.O. Box 16846-13114, Iran. \\ b. School of Civil Engineering, Iran University of Science and Technology, Narmak, Tehran, P.O. Box 16846-13114, Iran.
}

Received 29 July 2017; received in revised form 7 November 2017; accepted 13 January 2018

\author{
KEYWORDS \\ Offshore wind \\ turbines; \\ Monopile supporting \\ structures; \\ Engineering \\ optimization; \\ Structural design \\ optimization; \\ Meta-heuristic \\ algorithms.
}

\begin{abstract}
Considering both size and dimensions of the offshore wind turbine structures, design optimization of such structures is a fruitful yet, simultaneously, onerous task due to the tempestuous complexity of the problem, which mostly comes from their environment. However, in this study, a computerized methodology based on meta-heuristic algorithms, consisting of the Colliding Bodies Optimization (CBO), Enhanced Colliding Bodies Optimization (ECBO), and Vibrating Particle System (VPS), is presented such that more economic upshots can be accomplished. Hence, minimization of the total weight of the structure subjected to a number of structural constraints, including a frequency constraint, by applying the abovementioned algorithms is the underlying goal of this study. Using the data from Horns Rev I offshore wind farm, which is located in the coastlines of Denmark in the North Sea, this study is performed based on a simplified structural model of a monopile offshore wind turbine structure, which can be utilized in preliminary stages of pertinent projects for conducting suitable comparisons.

(C) 2019 Sharif University of Technology. All rights reserved.
\end{abstract}

\section{Introduction}

Significant increase in the population throughout the world and outstanding abatement in fossil fuel resources unearth the importance of supplanting the role of fossil fuels in supplying worldwide energy demands with new resources such as renewables. Considering the fact that wind is envisaged to be one of the most promising resources among renewables, wind turbines have engrossed much attention in recent years. In the past, the application of wind as an energy resource was solely materialized in onshore wind turbines. Although many advantages have been presented using

\footnotetext{
*. Corresponding author. Tel.: +982144202710;

Fax: +9821 rro240398

E-mail address: alikaveh@iust.ac.ir (A. Kaveh)
}

this approach, there are some hurdles hindering its application, including both visual and noise pollutions.

Moreover, substantial land occupancy of onshore wind turbines due to the noteworthy reduction in available lands near populated regions may additionally lead to a remarkable increase in required capitals. To overcome the mentioned barriers, offshore wind turbine concept was proposed. Increasing investments in offshore wind turbine industry, not only may the abovementioned problems be omitted, but also reaching noticeably longer and stronger wind resources has become viable, which has resulted in stronger reliance on such assets in some European countries such as United Kingdom and Germany [1].

Given two main categories of structural systems utilized in offshore wind industry, namely bottomfixed and floating support structures, the application of the former was commenced using monopiles. The popularity of these supporting structures can be re- 
vealed considering the fact that more than 65 percent of installed offshore wind turbines enjoy a monopile as their supporting structure. This popularity mostly comes from outstanding simplicity in both their design and production stages [2].

Higher potential of offshore wind resources has resulted in a noticeable increase in the size of offshore wind turbines compared to onshore wind structures; hence, design optimization of such structures would be an indispensable mission by which the required capitals may be substantially cut [3]. To do so, many approaches have been presented, which can be mainly categorized in two fundamental groups: (i) local optimizers and (ii) global optimizers. Local optimizer algorithms mostly employ gradient information or iterative methods in order to run an exploration within the solution space in the periphery of an initial point for obtaining better outcomes. The major disadvantages of the aforementioned method may be both significant hardship in implementation and the required time. Consequently, global optimizers such as meta-heuristic algorithms are proposed [4-5]. A number of these algorithms have recently been developed based on mimicking natural phenomena [6-7] and applied to optimization of challenging problems [8-15]. The main advantages of meta-heuristic algorithms are simplicity in implementation and less time-consumption.

Nevertheless, this research is performed based on three meta-heuristic algorithms; Colliding Bodies Optimization (CBO), Enhanced Colliding Bodies Optimization (ECBO), and Vibrating Particle System (VPS). Colliding Bodies Optimization (CBO) is a populationbased meta-heuristic algorithm, developed by Kaveh and Mahdavi [5], which attempts to mimic governing laws in collision between bodies. Palpable plainness in formulation and parameter independency are the main features of this algorithm. Enhanced Colliding Bodies Optimization (ECBO), which was introduced by Kaveh and Ilchi Ghazaan [16], utilizes a memory in order to enhance the CBO performance by saving some historically best solutions, which results in better performance in escaping from local minima without any increase in the computational cost. Vibrating Particle System (VPS) is a recently developed meta-heuristic algorithm introduced by Kaveh and Ilchi Ghazaan [7]. The damped-free vibration of single degree of freedom systems has inspired this population-based metaheuristic algorithm. It treats each solution candidate as a particle that seeks its equilibrium position.

Based on what has been mentioned so far, this study is aimed to indicate how meta-heuristic algorithms can be applied in preliminary design optimization of a monopile offshore wind turbine structure while considering some structural constraints. To do so, firstly a simplified model of such structures is introduced. Given the environmental load cases applied to offshore structures such as wave and wind loadings, the model is analyzed using finite element method by which internal stresses and nodal displacements can be subsequently determined. Fulfilling the considered constraints, the mentioned algorithms are utilized striving to discern the lowest possible weight for the structural elements while meeting all constraints. It should be mentioned that all steps of this study including modeling, loading, analysis, and optimization of the structure are established and developed using MATLAB.

\section{Configuration of a monopile offshore wind turbine structure and its simplified model}

Monopile offshore wind turbine structures are considered to be the simplest option in offshore wind industry. This type of offshore wind structures regularly comprises a cylindrical pile penetrating into the seabed, a transition piece that connects tower to the monopile, and typical components of each wind turbine such as nacelle, hub, rotor, and blades [2].

Since the main objective of this study is to provide a preliminary design optimization of monopile offshore wind turbine structures, a simplified model is defined based on the following assumptions:

- All the external equipment including cables, ladders, or working platforms, whether connected to the structure or not, is neglected;

- The transition piece is completely ignored in this study. In fact, considering the crucial role of transition piece in both structural integrity and structural performance of monopile structures, its special characteristics must be investigated in a detailed study; thus, in this research, the transition piece is considered to be made of a linear, elastic, and isotropic material, with the same structural properties as those of the whole structure;

- It is assumed that the structure is completely clamped at the bottom, meant for ignoring the soilstructure interaction. In other words, the penetration length of the monopile in the seabed soil is considered zero.

Monopile offshore wind turbine structures normally consist of a pile with constant diameter and a tapered tower in which the cross-section is continuously decreased from the bottom to the top of the structure. In this study, however, the whole structure is considered as a stepped tower. It means that the structure is made of several cylindrical circular segments with abrupt changes in sections [17]. In fact, the height of each segment is pre-defined and optimization algorithms are deployed having both diameter and thickness of each section as the design variables. 


\section{Applied loads to the structure and pertinent codes}

\subsection{Design standards and underlying principles}

All the environmental forces imposed on the structure, such as wind and wave actions, are assessed based on DNV standard in this study [18-19]. DNV standard is coded in accordance with partial safety factor method, satisfied under a linear combination of applied load cases to structures.

Given the limit state concept, offshore wind turbines must comply with the following states:

- Ultimate limit state: Failure of structures due to the paucity of sufficient capacity in bearing actions under miscellaneous load combinations;

- Serviceability limit state: Lack of capability of structures to work properly;

- Fatigue limit state: Failure of structures because of cyclic loads fatigue;

- Accidental Limit State: Failure of structures because of accidents like vessel impacts.

Among the aforementioned limit states, ultimate and serviceability limit states are the only ones taken into account in further steps of the present research.

\subsection{Applied load cases}

Wind turbines are of the most complex structures, which must resist several load cases including wind, earthquakes, gravity loadings, and, additionally, those that come from the operation of the wind turbine (Figure 1) [2]. Not only must an offshore wind turbine structure remain stable under several combinations of the mentioned actions, but also hydrodynamic loads, which emanate from different sources such as waves, currents, etc., are also applied to such structures. In fact, these effects cause high complexity in both analysis and design of offshore wind turbine structures compared to onshore wind turbines. In this study, however, the following load cases are the only ones taken into account:

- Permanent load cases: These loads are constant and invariable in any arbitrary design period. Wind turbine weight, tower weight, transition piece weight, and monopile weight are the most important permanent loads that are taken into consideration in the present research.

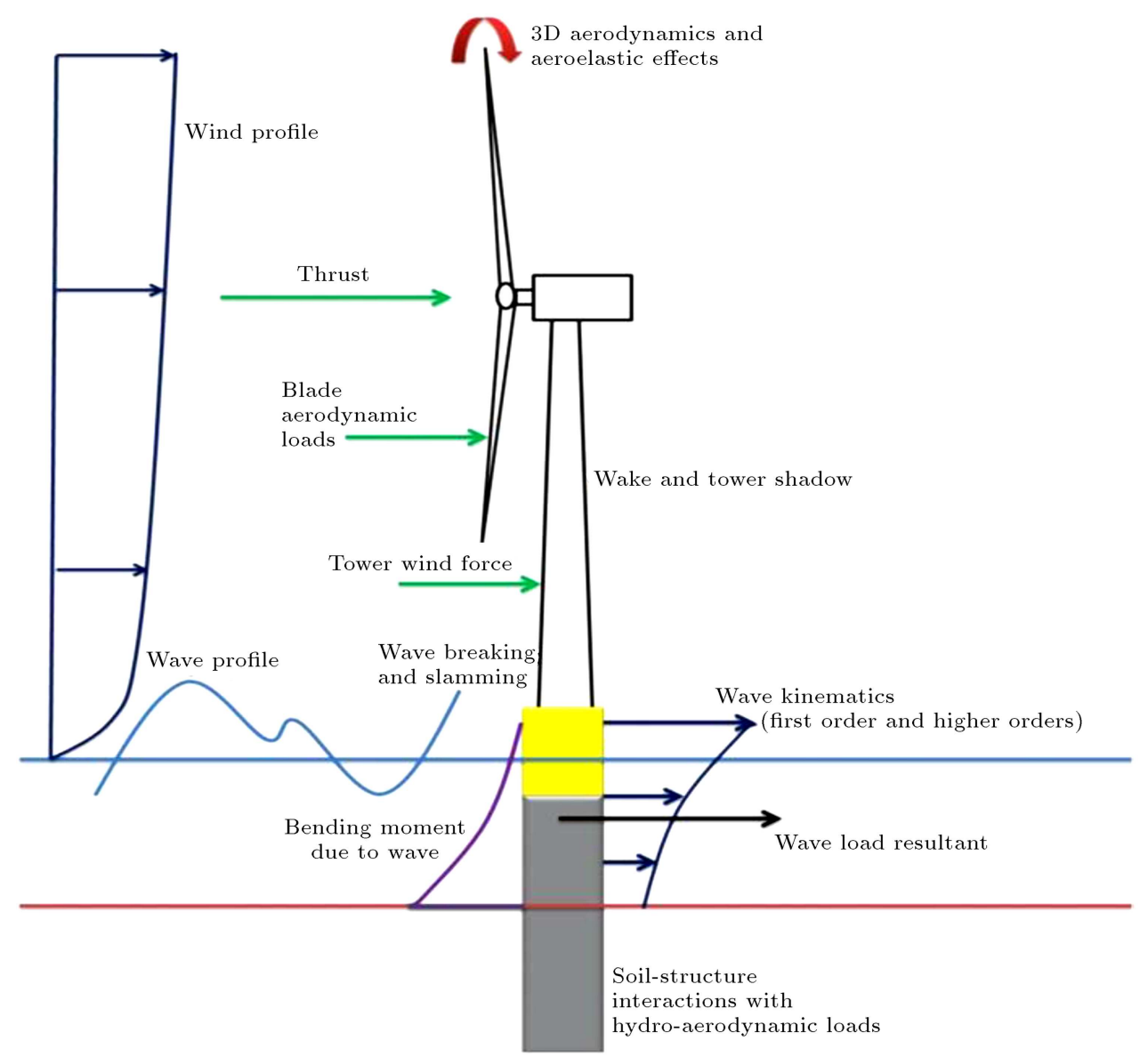

Figure 1. Aero-hydro-dynamic loads applied to an offshore wind structure [2]. 
- Environmental load cases: Numerous natural phenomena can affect the integrity of an offshore wind turbine structure, e.g., earthquakes, temperature, snow, ice, etc. In this study, however, wave, both wind-generated and tidal currents, and wind are the only considered environmental actions.

Quantification of the aforementioned environmental actions is briefly described in following subsections.

\subsubsection{Wave Loading}

In this study, quantification of the wave action is carried out using the well-known Morrison equation, which is a combination of theory and empiricism. It must be borne in mind that this equation is only applicable to the cases in which the dimension of the monopile is small compared to wavelength $(D<0.2 \lambda)$. Considering the typical wavelength of ocean waves, this stipulation is regularly met [2].

Based on Morrison equation, the total hydrodynamic load per unit length of a slender element consists in two terms, namely drag and inertia, which can be stated as follows [2]:

$$
d F=d F_{m}+d F_{d}=\frac{C_{m} \pi \rho D^{2}}{4} \dot{u}_{w} d z+\frac{C_{d} \rho D}{2}\left|u_{w}\right| u_{w} d z,
$$

where $d F_{m}$ is inertia force $(\mathrm{N} / \mathrm{m}), d F_{m}$ drag force $(\mathrm{N} / \mathrm{m}), C_{m}$ inertia coefficient, $C_{d}$ drag coefficient, $D$ element diameter $(\mathrm{m}), \rho$ mass density of sea water $\left(\mathrm{kg} / \mathrm{m}^{3}\right), u_{w}$ horizontal velocity of water particle $(\mathrm{m} / \mathrm{s})$, and $\dot{u}_{w}$ horizontal acceleration of water particle $\left(\mathrm{m}^{2} / \mathrm{s}\right)$.

Both drag and inertia coefficients are functions of relative roughness as well as Reynolds and KeuleganCarpenter numbers, which can be determined based on DNV standard [18]. In this study, these numbers are taken as 0.7 and 2 , respectively.

The next step is to find water particles kinematics. In order to assess horizontal velocity and acceleration of water particles, linear wave theory is employed (Figure 2). Based on linear wave theory, horizontal water particle kinematics are described as follows [2]:

$$
\begin{aligned}
& u_{x}=\omega \zeta_{a} \frac{\cosh k(h+z)}{\sinh k h} \cos (k x-\omega t), \\
& a_{x}=\omega^{2} \zeta_{a} \frac{\cosh k(h+z)}{\sinh k h} \sin (k x-\omega t),
\end{aligned}
$$

where $\omega$ is angular frequency $(\operatorname{Rad} / \mathrm{s}), \zeta_{a}$ wave amplitude $(\mathrm{m}), k$ wave number, $h$ water depth $(\mathrm{m})$, and $z$ the desired depth $(\mathrm{m})$.

It must be mentioned that since linear wave theory is only applicable up to the still water level $(z=0)$ and the wave kinematics of the upper levels are not established using this theory, Wheeler stretching approach is utilized for handling this problem [2]. Based on this model, the vertical coordinate must be superseded with the scaled coordinate, which is stated below [2]:

$$
z^{\prime}=(z-\zeta) \frac{h}{h+\zeta},
$$

where $\zeta=\zeta_{a} \cos (k x-\omega t)$ is instant wave elevation.

\subsubsection{Current loading}

Two types of currents are basically considered when assessing environmental loads imposed on offshore wind turbine structures, including both wind-generated and tidal currents, which are evaluated according to [18] as follows:

$$
\begin{aligned}
& v(z)=v_{\text {tide }}(z)+v_{\text {wind }}(z), \\
& v_{\text {tide }}(z)=v_{\text {tide } 0} \times\left(\frac{h+z}{h}\right)^{\frac{1}{7}}, \\
& v_{\text {wind }}(z)=v_{\text {wind } 0} \times\left(\frac{h_{0}+z}{h_{0}}\right), \\
& v_{\text {wind } 0}=k \times U_{0},
\end{aligned}
$$

where $k$ ranges from 0.015 to $0.03, U_{0}$ is 1 -hour mean wind speed at $10 \mathrm{~m}$ of height $(\mathrm{m} / \mathrm{s}), h$ water depth $(\mathrm{m})$, $h_{0}$ reference depth from wind generated current (50 $\mathrm{m}), v_{\text {wind } 0}$ wind generated current at still water level $(\mathrm{m} / \mathrm{s}), v_{\text {tide0 }}$ tidal current at still water level $(\mathrm{m} / \mathrm{s})$, and $z$ vertical coordinate from still water level $(\mathrm{m})$.

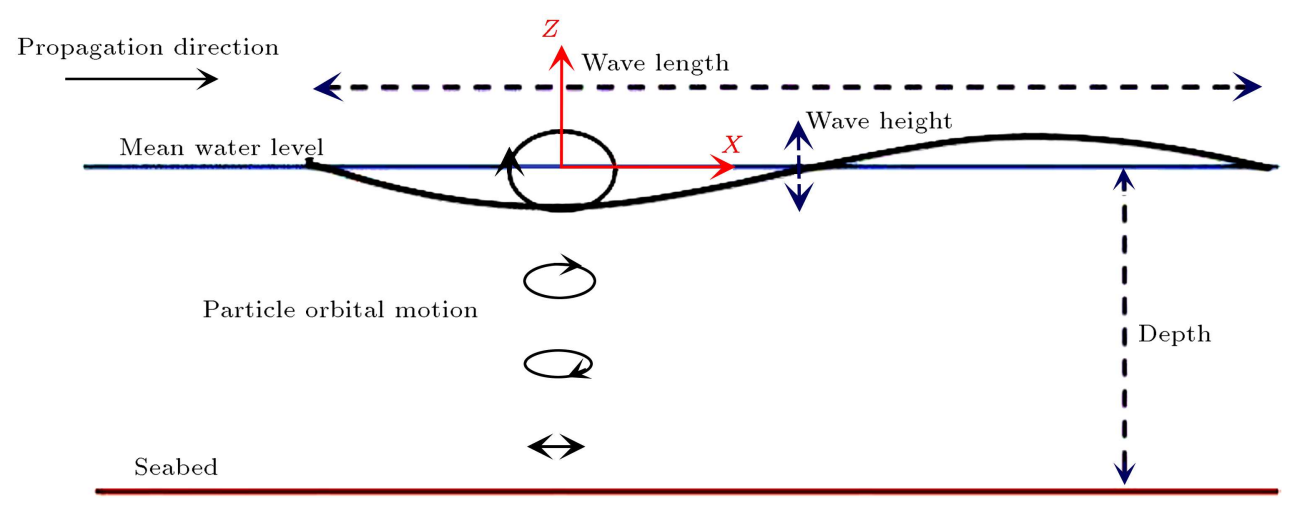

Figure 2. Linear wave theory (Airy theory) [2]. 
In order to take the current loading into account, the current velocities must be incorporated in evaluating the drag term of Morrison equation [20].

$$
F_{d}=\frac{1}{2} C_{d} \times \rho_{w} \times D \times\left(\left|u+U_{c}\right|\right) \times\left(u+U_{c}\right),
$$

where $u$ is horizontal water particle velocity $(\mathrm{m} / \mathrm{s})$ and $U_{c}$ is current velocity $(\mathrm{m} / \mathrm{s})$.

\subsubsection{Wind loading}

Wind force on tower

According to DNV standard, wind force on the structural elements of wind turbine towers can be found using the subsequent formula [18]:

$$
F=\frac{1}{2} \times \rho_{a} \times C_{S} \times S \times U^{2}
$$

where $\rho_{a}$ is air density $\left(\mathrm{kg} / \mathrm{m}^{3}\right), C_{S}$ shape coefficient, $S$ projected area of the member normal to the direction of the force $\left(\mathrm{m}^{2}\right)$, and $U$ wind velocity $(\mathrm{m} / \mathrm{s})$.

Note that shape coefficient in this study is considered 0.7. Additionally, given the wind conditions described in DNV standard-Normal Wind Condition and Extreme Wind Condition-since considering extreme wind condition results in more severe forces in the structure, this scenario is adopted for assessing wind actions in this study [21].

Wind is inherently a dynamic phenomenon. That is, not only is wind velocity altered in different altitudes, but also velocities recorded by an anemometer in a certain height vary with time. Considering the abovementioned fact, quantification of wind velocity under extreme wind condition can be carried out using the following formulae [18]:

$$
\begin{aligned}
& C=5.73 \times 10^{-2} \times \sqrt{1+0.15 \times U_{0}}, \\
& I_{U}=0.06 \times\left(1+0.043 \times U_{0}\right) \times\left(\frac{z}{h}\right)^{-0.22}, \\
& U(T, z)=U_{0} \times\left\{1+C \times \ln \left(\frac{z}{h}\right)\right\} \\
& \times\left\{1-0.41 \times I_{U} \times \ln \left(\frac{T}{T_{0}}\right)\right\},
\end{aligned}
$$

where $U_{0}$ is 1-hour wind mean speed at $10 \mathrm{~m}$ of height $(\mathrm{m} / \mathrm{s}), h$ is $10 \mathrm{~m}, T_{0}$ is 3600 seconds, $T<T_{0}$ is the desired time (s), and $z$ is the desired height from still water level $(\mathrm{m})$.

\section{Wind Force on Rotor and Blades}

Modern wind turbines are equipped with some control systems by which power production rate and wind loads on the structure can be controlled so that the occurrence of tentative damages due to the increment in wind velocity and, subsequently, wind force can be

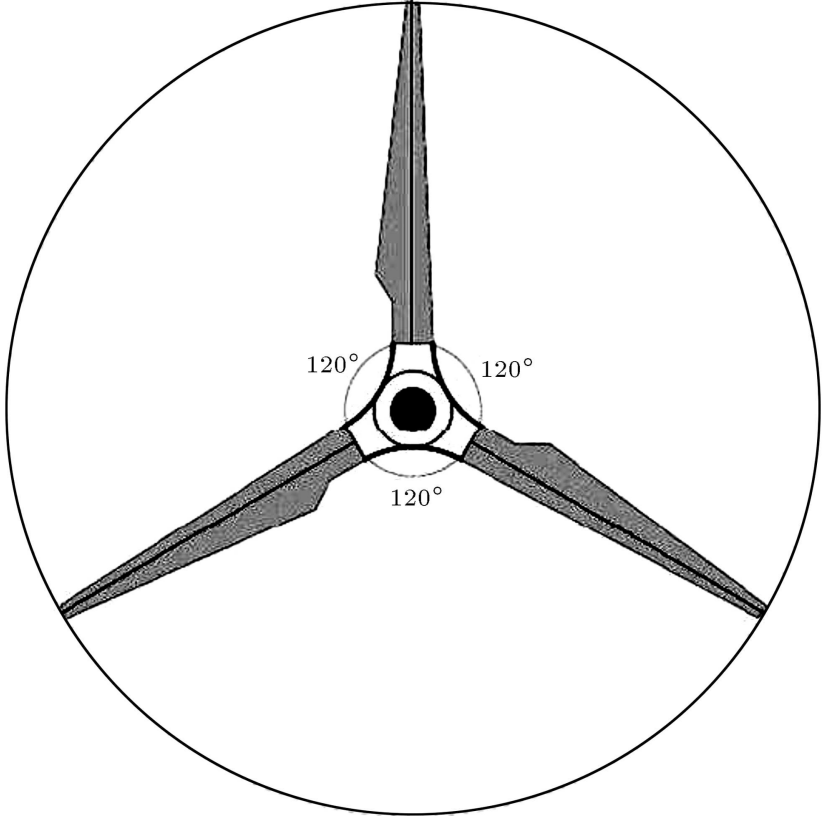

Figure 3. The most unfavorable position of rotor in stopped mode [21].

prevented. In fact, these systems are directly responsible for establishment of both start-up and shutdown commands in wind turbines when reaching the cut-in and cut-out wind speeds, respectively. Indeed, the operation of wind turbines is entirely ceased if the current wind speed exceeds cut-out wind limit [2]. Since the stopped mode obviously results in more severe forces than the operation mode does, aerodynamic forces are evaluated based on this mode in this study. In this case, the most unfavorable position of blades is depicted in Figure 3 [21]. Based on blade element theory, drag and lift forces in each blade can be determined as follows (Figure 4) [20]:

$$
\begin{aligned}
& F_{L}=\frac{1}{2} \times C_{L}(\alpha) \times \rho_{a i r} \times V_{\mathrm{Rel}}^{2} \times c_{a} \times \Delta r, \\
& F_{D}=\frac{1}{2} \times C_{D}(\alpha) \times \rho_{a i r} \times V_{\mathrm{Rel}}^{2} \times c_{a} \times \Delta r \\
& V_{\mathrm{Rel}}=\sqrt{V_{\text {Disk }}^{2}+V_{\text {Rot }}^{2}}, \\
& a=\frac{V_{0}-V_{D i s k}}{V_{0}} \\
& V_{\text {Rot }}=\Omega \times r
\end{aligned}
$$

where $F_{L}$ is aerodynamic lift $(\mathrm{N}), F_{D}$ aerodynamic drag $(\mathrm{N}), C_{L}(\alpha)$ aerodynamic lift coefficient, $C_{D}(\alpha)$ aerodynamic drag coefficient, $\rho_{\text {air }}(\alpha)$ mass density of air $\left(\mathrm{kg} / \mathrm{m}^{3}\right), c_{a}$ airfoil chord length $(\mathrm{m}), \Delta r$ radial length of blade element (m), $\alpha$ angle of attack (deg), $\Omega$ angular rotational speed ( $\mathrm{rad} / \mathrm{s}), V_{0}$ upstream wind velocity $(\mathrm{m} / \mathrm{s}), V_{D i s k}$ wind velocity at airfoil $(\mathrm{m} / \mathrm{s}), a$ 


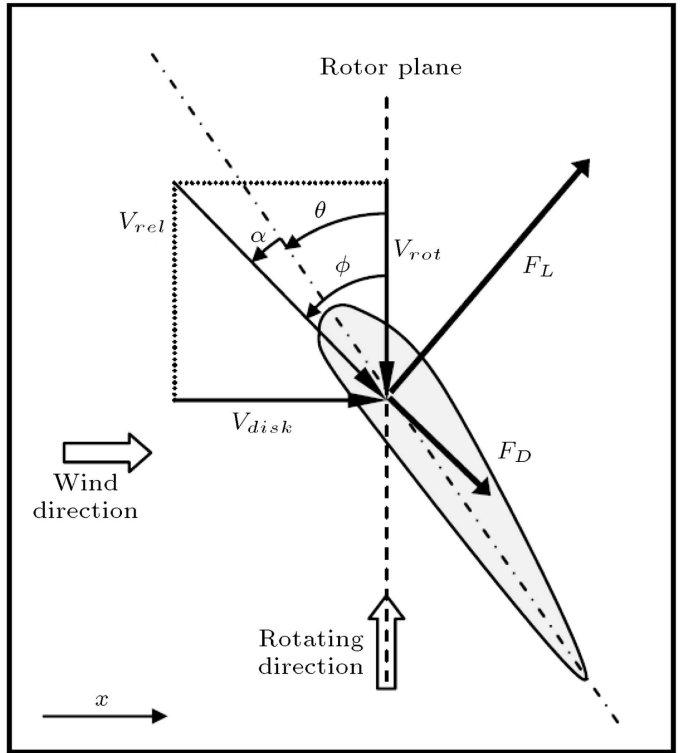

(a)

Figure 4. (a) System of forces acting on a blade.

induction factor, and $r$ distance of blade element from axis of rotation $(\mathrm{m})$.

Finally, total load in $x$-direction in each blade can be calculated as [20]:

$$
\begin{aligned}
& F_{x}=F_{L} \cos \phi+F_{D} \sin \phi, \\
& V_{a x}=N_{b} \sum_{r=\text { root }}^{r=t i p} F_{x, r} .
\end{aligned}
$$

The moment acting on the top of the structure can then be found to satisfy equilibrium of moments.

\subsection{Load combinations}

By the assumption that changes in wave and wind forces do not have any correlations, linear combination approach can be adopted when combining miscellaneous load cases. DNV standard describes the following load combinations for designing wind turbine structures under ultimate limit state. Note that serviceability limit state criteria must be fulfilled under a load combination in which all the coefficients of different load cases are considered as unity [21].

\section{First Load Combination}

Dead load (containing self-weight of the whole structure including tower weight, pile weight, and wind turbine weight multiplied by a coefficient equal to 1.25) + wind load (consisting of both wind loads imposed on tower and turbine multiplied by a coefficient equal to 0.7 ) + wave load (multiplied by a coefficient equal to $0.7)$.

\section{Second Load Combination}

Dead load (containing self-weight of the whole structure including tower weight, pile weight, and wind

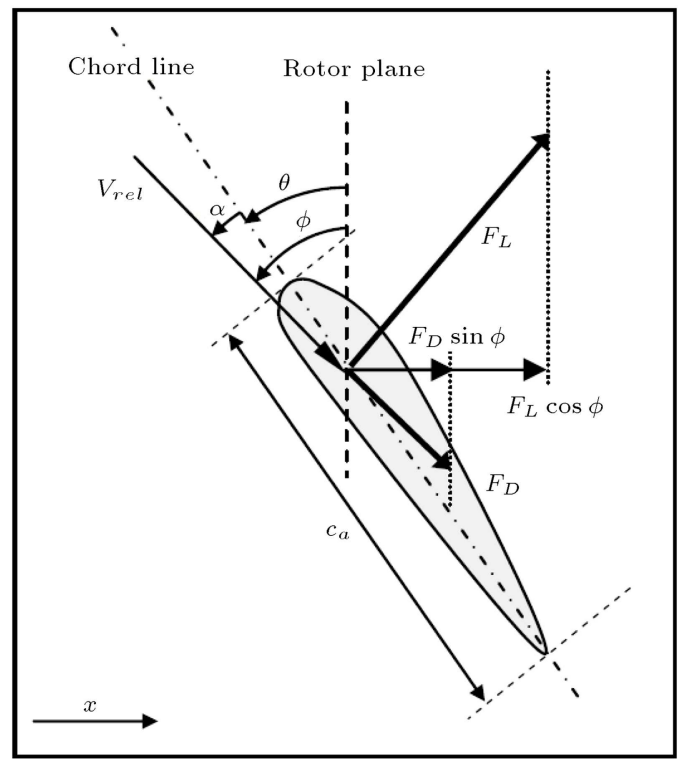

(b)

(b) Resulting lift and drag forces in $x$-axis direction [20].

turbine weight multiplied by a coefficient equal to 1 ) + wind load (consisting of both wind loads imposed on tower and turbine multiplied by a coefficient equal to $1.35)$ + wave load (multiplied by a coefficient equal to $1.35)$.

\section{The monopile offshore wind turbine structure optimization problem}

\subsection{Optimization problem}

A typical structural optimization problem can be stated as follows [4]:

$$
\begin{aligned}
& \text { Find } X=\left[x_{1}, x_{2}, x_{3}, x_{4}, \ldots, x_{n}\right] \\
& \text { To minimize } \operatorname{Mer}(X)=f(X) \times f_{\text {penalty }}(X) \\
& \text { Subjected to } \quad g_{i}(X) \leq 0, \quad i=1,2, \ldots, m \\
& x_{i \min } \leq x_{i} \leq x_{i \max },
\end{aligned}
$$

where $X$ is the vector of design variables with $n$ unknowns and $g_{i}$ is the $i$ th constraint from $m$ inequality constraints. For the sake of simplicity, in this study, the well-known penalty approach is adopted for constraint handling, where $\operatorname{Mer}(X)$ is the merit function, $f(x)$ is the cost function, and $f_{\text {penalty }}(X)$ accounts for constraint violations. Additionally, the values of design variables are restricted to $x_{i, \min }$ and $x_{i, \max }$, being the lower and upper bounds of variables, respectively. In present research, the following penalty function is used to transform a constrained optimization problem into an unconstrained one: 


$$
f_{\text {penalty }}(X)=\left(1+\varepsilon_{1} \sum_{i=1}^{m} \max \left(0, g_{i}(X)\right)\right)^{\varepsilon_{2}} .
$$

The parameters $\varepsilon_{1}$ and $\varepsilon_{2}$ in the penalty function are chosen considering both exploration and exploitation rates within the search space in algorithms. The parameter $\varepsilon_{1}$ in the utilized penalty function is chosen as unity. In addition, $\varepsilon_{2}$ is selected 1.5 at the start, which linearly increases to 3 in the first approach and to 10 in the second one.

\subsection{Design variables}

As mentioned, both diameter and thickness of each part of the structure are considered as the design variables in the present research.

$$
X=\left[D_{1}, D_{2}, \ldots, D_{n}, t_{1}, t_{2}, \ldots, t_{n}\right] .
$$

Therefore, it can be conceived that the design variable vector consists of $2 n$ variables, in which $n$ is the number of segments. Furthermore, note that $D_{i}$ and $t_{i}$ are the diameter and thickness of the $i$ th part, respectively.

\subsection{Design constraints}

Generally, design constraints can be categorized into many different groups such as serviceability, stability, and stress constraints. In this study, two different design constraints are considered for controlling serviceability of the structure, while the same number for them is aimed to control both local and global stability of the structure. Finally, internal stresses in different sections of the structure are assessed and controlled with their capacity as the stress constraint.
As the first serviceability design constraint, the fundamental frequency of the structure is assessed and controlled with the recommended values. Since monopile offshore wind turbine structures are sensitive to dynamic excitements due to their slenderness and the nature of their environment, only by restricting dynamic behavior of such structures may the occurrence of unwilling phenomena such as resonance be precluded. The soft-stiff range determined in Figure 5 is presumed to be the best gamut in which the fundamental frequency of offshore wind turbine structures can be accommodated, where " $1 P$ " frequency represents the rotational frequency of turbine in the operation mode and " $3 P$ " denotes the blade-passing frequency, accounting for shadowing effects. The former mostly takes place between $0.17-0.33 \mathrm{~Hz}$ and the latter for a turbine with three blades usually happens between $0.5 \mathrm{~Hz}$ and $1 \mathrm{~Hz}$. The desired interval in this study is assumed to be within $0.32-0.54 \mathrm{~Hz}$ [21-22].

Note that, in this study, two different structural approaches are utilized for finding the fundamental frequency of the structure. As the first approach, the structure is reduced into a simplified 2D dynamic model in which each segment is considered as a frame element. Each node of these elements contains 3 degrees of freedom: one horizontal translation, one vertical translation, and one planar rotation. The mass matrix of each segment is then obtained using consistent mass formulae. The mass and stiffness matrices of the entire structure are subsequently accomplished using an assembling approach [17].

As the other approach, the fundamental frequency of the structure is simply calculated using the following

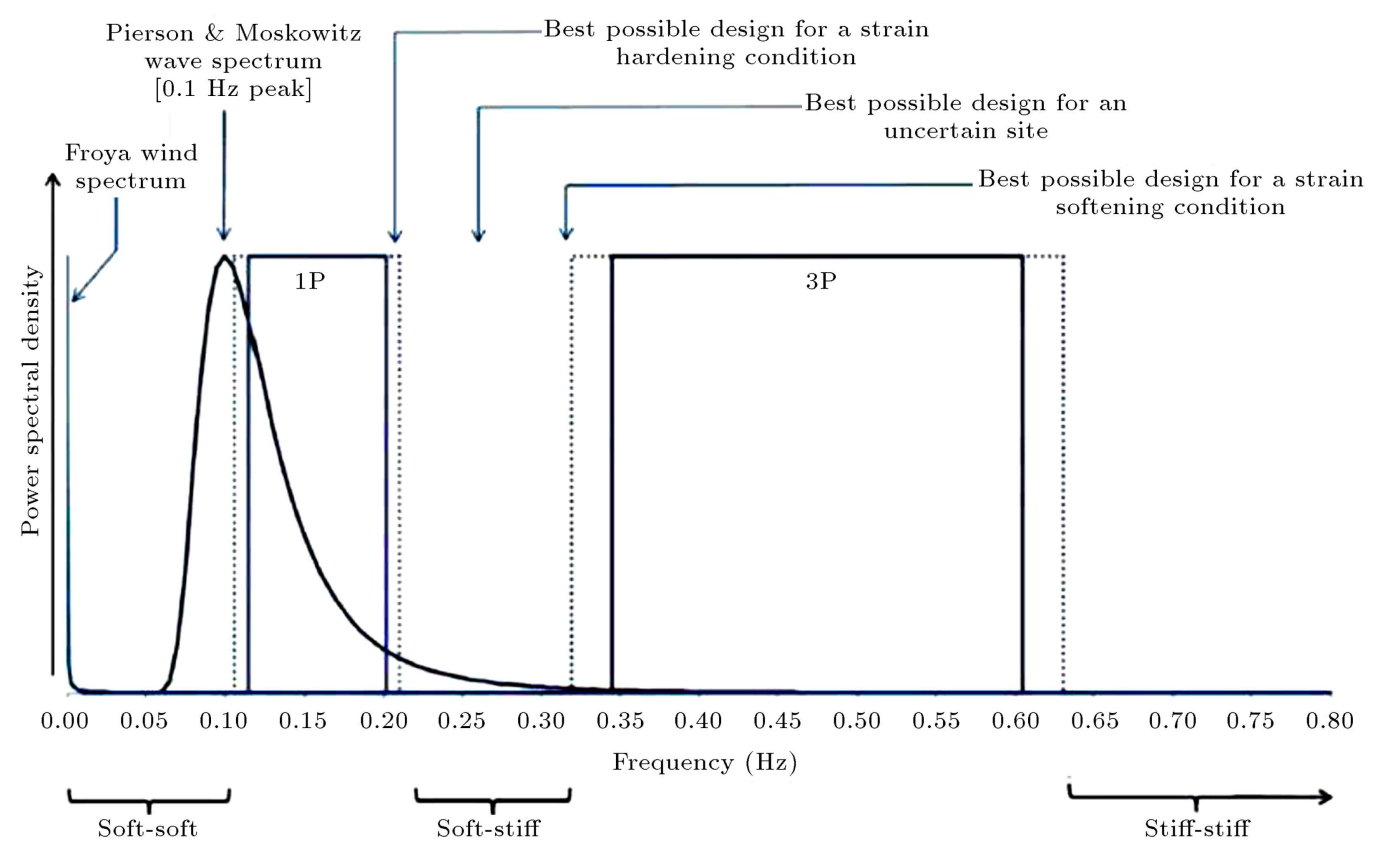

Figure 5. Frequency spectrum of the dynamic loads [21]. 
estimation [20]:

$$
f_{\text {nat }}^{2}=\frac{3.04}{4 \times \pi^{2}} \times \frac{E I}{\left(0.227 \times \mu \times L+m_{t o p}\right) \times L^{3}},
$$

where $f_{\text {nat }}$ is fundamental frequency $(\mathrm{Hz}), m_{\text {top }}$ turbine mass $(\mathrm{kg}), \mu$ structure mass per meter $(\mathrm{kg} / \mathrm{m}), L$ structure length $(\mathrm{m})$, and $E I$ tower bending stiffness (N.m $\left.{ }^{2}\right)$.

It must be borne in mind that in this approximation, since the simplified model contains several segments with different diameters and thicknesses, as a conservative assumption, bending stiffness of the structure is determined using averaged diameter and thickness.

Dynamic effects of vortex shedding are also taken into account in this study. Coincidence of the fundamental frequency of the structure with the frequency of shedding vortices may result in resonance, which must be prevented. To do so, the following constraint inequality must be fulfilled [23-24]:

$$
U_{C r} \leq 0.2 \times U_{\text {Project }},
$$

where $U_{C r}$ is critical wind velocity $(\mathrm{m} / \mathrm{s})$ and $U_{\text {Project }}$ is project wind velocity $(\mathrm{m} / \mathrm{s})$.

The critical wind velocity is approximately obtained using the following formula [23-24]:

$$
U_{C r}=f \times \frac{D}{S_{t}}
$$

where $f$ is natural frequency of the structure $(\mathrm{Hz}), D$ element diameter $(\mathrm{m})$, and $S_{t}$ Strouhal number, which is taken as 0.2 in this study.

The second serviceability constraint is aimed to restrict the amount of lateral displacement at the top of the tower, which may hinder the performance of wind turbine. This displacement must be limited to less than one percent of the total length of the structure in accordance with DNV [21].

The next set of design constraints is to control the stability of the structure in both local and general scales. These constraints are developed based on Eurocode 3 [25]. To ensure that local instability will not take place, the following in equality must be fulfilled in all sections. Global stability is also controlled complying with EC3 [25].

$$
\frac{D_{i}}{t_{i}} \leq 90
$$

Conclusively, the next design constraint states that the summation of axial and bending stresses in all sections could not exceed the yield strength of the utilized steel, which is described as follows [25]:

$$
\frac{N_{E d}}{A}+\frac{M_{E d}}{A} \times y \leq \sigma_{y} .
$$

\subsection{Cost function}

Cost function or the total weight of structure is established below:

$$
f(X)=\sum_{i=1}^{n} \rho g V_{i}=\sum_{i=1}^{n} \rho g A_{i} L_{i}=\sum_{i=1}^{n} \rho g\left(\pi D_{i} t_{i} L_{i}\right)
$$

\section{Utilized meta-heuristic algorithms}

Given the complexity of loading and design constraints of offshore wind turbine structures, design optimization of such structures is an expensive task. To overcome this hurdle, in the present research, three simple yet efficient meta-heuristic algorithms, namely colliding bodies optimization, enhanced colliding bodies optimization, and vibrating particle system, are used to cover the required demands. The abovementioned algorithms are briefly introduced here.

\subsection{Colliding bodies optimization algorithm}

Colliding Bodies Optimization (CBO) is a recently developed meta-heuristic algorithm that mimics the momentum and energy conservation laws in onedimensional collision between bodies. This algorithm is a multi-agent algorithm containing a number of Colliding Bodies (CBs) with determined mass and velocity [5]. After collision, CBs move toward new positions, having new velocities corresponding to old velocities, masses, and coefficient of restitution. The algorithm is initialized by random selection of agents within the search space. Sorting agents in accordance with the values of cost function in an ascending manner, CBs are then divided into two equal categories named stationary and moving groups (Figure 6). Good agents in accordance with the objective function are considered as stationary agents, whose velocity before collision is considered equal to zero. The members of the moving category move towards stationary ones before occurrence of the collision. The collision happens in a way that the better and worse CBs collide with each other, which results in improving the positions of moving and forcing stationary CBs, simultaneously. Velocity of the CBs before collision is considered as the

$$
X_{i}=\{\overbrace{X_{X_{1}} \ldots X_{n}}^{\text {Stationary CBs }} \overbrace{X_{n+1} \ldots X_{2 n}}^{\text {Moving CBs }}\}
$$

(a)

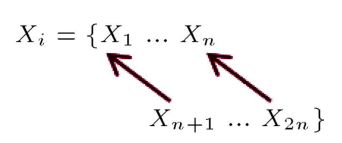

(b)

Figure 6. (a) The sorted CBs in an ascending order. (b) The pairs of objects for the collision [15]. 
value of change in the body position [5].

$$
\begin{aligned}
& v_{i}=0, \quad i=1,2, \ldots, n, \\
& v_{i}=x_{i}-x_{i-n}, \quad i=n+1, n+2, \ldots, 2 n .
\end{aligned}
$$

Afterwards, momentum and energy conservation laws are employed for finding the velocity of each body after collision.

$$
\begin{aligned}
& v_{i}^{\prime}=\frac{\left(m_{i+n}+\varepsilon m_{i+n}\right) v_{i+n}}{m_{i}+m_{i+n}}, \quad i=1,2, \ldots, n, \\
& v_{i}^{\prime}=\frac{\left(m_{i}-\varepsilon m_{i-n}\right) v_{i}}{m_{i}+m_{i+n}}, \quad i=n+1, n+2, \ldots, 2 n .
\end{aligned}
$$

In the abovementioned formulae, $v_{i}$ and $v_{i}^{\prime}$ are the velocities of the $i$ th $\mathrm{CB}$ before and after collision, respectively. Additionally, the mass of each $\mathrm{CB}$ is determined as follows:

$$
m_{k}=\frac{\frac{1}{f i t(k)}}{\sum_{i=1}^{n} \frac{1}{f i t(i)}}, \quad k=1,2, \ldots, 2 n,
$$

where $f i t(i)$ is the value of objective function for the $i$ th agent. It can be concluded that good and bad CBs carry larger and smaller masses, respectively. Replacing $f i t(i)$ with its adverse results in maximization of the objective function using the same algorithm. Coefficient of restitution $(\varepsilon)$, which is defined as the ratio of separation velocity of two agents after collision to their approach velocity before collision, is mostly responsible for controlling the rates of exploration and exploitation in the algorithm, defined as follows:

$$
\varepsilon=1-\frac{i t e r}{\text { iter }_{\max }}
$$

where iter and iter $_{\max }$ are the actual iteration number and the maximum number of iterations, respectively. Finally, the new positions of CBs can be determined using the following formulae:

$$
\begin{aligned}
& X_{i}^{\text {new }}=x_{i}+\operatorname{rand} \circ v_{i}^{\prime} \quad i=1,2, \ldots, n, \\
& x_{i}^{\text {new }}=x_{i-n}+\operatorname{rand} \circ v_{i}^{\prime} \quad i=n+1, n+2, \ldots, 2 n .
\end{aligned}
$$

The optimization process is terminated when reaching a predefined evaluation number, such as maximum number of iterations.

\subsection{Enhanced colliding bodies optimization algorithm}

To improve the CBO performance, enhanced colliding bodies optimization is developed utilizing memory in order to save some historically best $\mathrm{CBs}$, which results in obtaining better solutions consuming less time. Additionally, a mechanism is defined to change some components of CBs randomly for providing the CBs with the opportunity to escape from local minima and prevent probable premature convergence. This algorithm is mentioned as follows [16]:

\section{- Level 1: Initialization}

Step 1: The initial positions of all the colliding bodies are randomly determined within the search space.

\section{- Level 2: Search}

Step 1: Each CB needs to be assigned a mass value based on Eq. (32);

Step 2: Colliding Memory (CM) is used to save a number of best-so-far vectors and their related mass and objective function values. Solution vectors that are saved in $\mathrm{CM}$ are added to the population and, consequently, the same number for the current worst CBs is discharged from the population. Afterwards, CBs are sorted based on their corresponding objective function values in an ascending order;

Step 3: CBs are divided into two equal groups: (i) stationary group, and (ii) moving group;

Step 4: The velocity of moving CBs before collision is calculated in this step using Eq. (30). Note that the velocity of stationary CBs before collision is zero;

Step 5: The velocities of both stationary and moving bodies after collision are calculated using Eq. (31);

Step 6: Eq. (34) determines the new position of each CB after collision;

Step 7: In order to escape from local minima, a parameter called Pro is defined within $(0,1)$, which specifies whether a component of each CB must be changed or not. For each colliding body, Pro is compared with $r n_{i}(i=1,2, \ldots, n)$, which is a random number uniformly distributed within $(0,1)$. If $r n_{i}<$ Pro, one design variable of the $i$ th CB is selected randomly and its value is regenerated using the subsequent formula:

$$
x_{i j}=x_{i, \min }+\text { random } \circ\left(x_{j, \max }-x_{j, \min }\right) \text {, }
$$

where $x_{i j}$ is the $j$ th design variable of the $i$ th CB, and $x_{j, \max }$ and $x_{j, \min }$ are the upper and lower bounds of the $j$ th variable, respectively. To protect the structure of CBs, only one dimension is altered.

\section{- Level 3: Terminal Condition}

Step 1: The optimization process is ceased when reaching a predefined maximum evaluation number.

\subsection{Vibrating particle system algorithm}

The vibrating particle system is a meta-heuristic algorithm, which is developed based on the free vibration 
of single degree of freedom systems with viscous damping. This algorithm comprises a number of particles, which are randomly chosen within an $n$-dimensional search space, gradually approaching their equilibrium positions [7]. The steps involved in this algorithm are as follows:

Step 1: The VPS parameters are chosen and the initial positions of all particles are randomly selected in an $n$-dimensional search space;

Step 2: The objective function is calculated for each particle;

Step 3: Three equilibrium positions which each particle is inclined to approach are defined with different weights: (i) the best position achieved so far among the entire population $(H B)$, (ii) a Good Particle $(G P)$, and (iii) a Bad Particle $(B P)$. To determine $G P$ and $B P$ for each candidate, the current population is ascendingly sorted in accordance with the objective function values, and then $G P$ and $B P$ are randomly chosen from the first and second halves, respectively [7].

Additionally, in order to model the effect of damping on the algorithm, a descending function, which is commensurate with the number of iterations, is proposed as follows:

$$
D=\left(\frac{i t e r}{i t e r_{\max }}\right)^{-\alpha},
$$

where iter is the current iteration number, iter $\max$ is the total number of iterations, and $\alpha$ is a constant number.

Based on the proposed concept (free vibration of single degree of freedom systems), the positions are updated using the following formulae:

$$
\begin{aligned}
x_{i}^{j}= & w_{1}\left[\text { D.A.rand } 1+H B^{j}\right] \\
& +w_{2}\left[\text { D.A.rand } 2+G P^{j}\right] \\
& +w_{3}\left[\text { D.A.rand } 3+B P^{j}\right], \\
A= & {\left[w_{1} \cdot\left(H B^{j}-x_{i}^{j}\right)\right]+\left[w_{2} \cdot\left(G P^{j}-x_{i}^{j}\right)\right] } \\
& +\left[w_{3} \cdot\left(B P^{j}-x_{i}^{j}\right)\right], \\
w_{1}+ & w_{2}+w_{3}=1,
\end{aligned}
$$

where $x_{i}^{j}$ is the $j$ th variable of particle $i ; w_{1}, w_{2}$, and $w_{3}$ are the parameters measuring the relative importance of $H B, G P$, and $B P$, respectively; and rand 1 , rand 2 , and rand 3 are numbers randomly distributed within $(0,1)$. Additionally, a parameter called $p$ is randomly defined within $(0,1)$, specifying whether the effect of $B P$ must be considered when updating particles or not. It is compared with a random number (rand), which is distributed randomly within $(0,1)$. If $p<$ rand, then $w_{3}$ is considered zero and $w_{2}=1-w_{1}[7]$;

Step 4: As the process proceeds, the particle seeks better results within the search space. When violating a constraint, the corresponding component must be regenerated using harmony search-based side constraint-handling approach;

Step 5: Steps 2 to 4 are repeated until fulfilling a termination criterion, such as the maximum number of iterations.

\section{Design example and results}

\subsection{Design example}

The present study is performed based on a simplified model of monopile offshore wind turbine structures constructed in coastlines of Denmark in the North Sea as members of the Horns Rev I offshore wind farm [21]. The required characteristics can be found in Table 1 .

The design example is considered as a 83.5 meters high tower, made of steel with structural properties of $f_{y}=235 \mathrm{MPa}, E=2 \times 10^{5} \mathrm{MPa}$, and $\rho=7885 \mathrm{~kg} / \mathrm{m}^{3}$, whose height is divided into 21 parts including six $2 \mathrm{~m}$ high, one $1.5 \mathrm{~m}$ high, and fourteen $5 \mathrm{~m}$ high parts from the bottom to the top of the structure, respectively. Thus, the height vector of the design example can be written as follows:

$$
\begin{aligned}
H= & \left\{H_{1}, H_{2}, \ldots, H_{21}=\{2,2,2,2,2,2,1.5,5,5,5\right. \\
& 5,5,5,5,5,5,5,5,5,5,5,5,5\}\} m
\end{aligned}
$$

\subsection{Loading}

\subsubsection{Gravity loads}

The weight of the original structure before optimization can be determined referring to [21], considering the same assumptions as those of this study, which are indicated in Table 2. In addition, environmentally applied loads to the structure are calculated in accordance with the meta-ocean data of the location shown in Table 3.

\subsubsection{Hydrodynamic Loading}

To assess hydrodynamic loads, the following assumptions are made:

- In assessing the hydrodynamic loads using Morrison equation, it is assumed that both drag and inertia terms simultaneously take place;

- Hydrodynamic loads are evaluated based on the maximum wave height resulting in the worst scenario;

- It is believed that the phase angle, $\pi / 4$, yields more 
Table 1. Horns Rev I data adopted from [21].

\begin{tabular}{|c|c|c|}
\hline Turbine & Turbine manufacture & Vestas wind systems \\
\hline & Turbine model & Vestas V80-2.0 MW \\
\hline \multirow[t]{3}{*}{ Operational } & Cut-in wind speed & $4 \mathrm{~m} / \mathrm{s}$ \\
\hline & Rated wind speed & $16 \mathrm{~m} / \mathrm{s}$ \\
\hline & Cut-out wind speed & $25 \mathrm{~m} / \mathrm{s}$ \\
\hline \multirow[t]{9}{*}{ Rotor and Hub } & Rotor type & 3-bladed, 86orizontal axis \\
\hline & Rotor position & Upwind \\
\hline & Rotor diameter & $80 \mathrm{~m}$ \\
\hline & Rotor area & $5027 \mathrm{~m}^{2}$ \\
\hline & Rotor speed (min) & $108 \mathrm{rpm}$ \\
\hline & Rotor speed (Rated) & $16.7 \mathrm{rpm}$ \\
\hline & Rotor speed (max) & $19.1 \mathrm{rpm}$ \\
\hline & Rotor weight (incl. hub) & 20 ton \\
\hline & Hub height (above MSL) & $70 \mathrm{~m}$ \\
\hline \multirow[t]{4}{*}{ Blades } & Blade tip height (above MSL) & $110 \mathrm{~m}$ \\
\hline & Blade length & $39 \mathrm{~m}$ \\
\hline & Blade max chord (max width) & $3.5 \mathrm{~m}$ \\
\hline & Weight pr. blade & 6.5 ton \\
\hline Nacelle & Nacelle weight & 79 ton \\
\hline \multirow[t]{3}{*}{ Tower } & Structure type & Tubular steel tower \\
\hline & Height & $61 \mathrm{~m}$ \\
\hline & Weight & 160 ton \\
\hline \multirow[t]{5}{*}{ Substructure } & Structure type & Steel monopile \\
\hline & Transition piece structure description & Diameter: $4.2 \mathrm{~m}$; length: $18 \mathrm{~m}$ \\
\hline & Support structure description & Diameter: $4 \mathrm{~m}$; thickness: $5 \mathrm{~cm}$ \\
\hline & Foundation type & Piled \\
\hline & Foundation structure description & The monopiles are driven $25 \mathrm{~m}$ into seabed \\
\hline
\end{tabular}

Table 2. Gravity loads of the structure before optimization [21].

\begin{tabular}{cc}
\hline Rotor and hub weight $(\mathrm{kN})$ & 196.13 \\
3-blade weight $(\mathrm{kN})$ & 191.23 \\
Nacelle weight $(\mathrm{kN})$ & 774.72 \\
Tower weight $(\mathrm{kN})$ & 2189.08 \\
Monopile weight until seabed level $(\mathrm{kN})$ & 1076.06 \\
Total weight of the structure from the top to the seabed level $(\mathrm{kN})$ & 4427.24 \\
\hline
\end{tabular}

Table 3. Environmental inputs of [21] utilized in this study.

\begin{tabular}{ccc}
\hline Wave & Maximum wave height $(\mathrm{m})$ & 8.1 \\
Wave period $(\mathrm{s})$ & 12 \\
Water depth $(\mathrm{m})$ & 13.5
\end{tabular}

Wind 1-hour mean wind speed at 10 meters height $(\mathrm{m} / \mathrm{s}) \quad 28.8$

$\begin{array}{lll}\text { Current Tidal current velocity at still water level }(\mathrm{m} / \mathrm{s}) \quad 0.5 & 0.5\end{array}$


severe forces. Hence, all the hydrodynamic actions are assessed in this phase angle [21].

Note that the density of water for assessing hydrodynamic loads is considered $1025 \mathrm{~kg} / \mathrm{m}^{3}$ wherever it is needed.

\subsubsection{Aerodynamic loading}

As mentioned, aerodynamic forces in this study are calculated considering the stopped mode under extreme wind condition. The blades of this wind turbine are presumed to be made of NACA-N63-212 airfoil due to lack of information (Figure 7); thus, the drag and lift coefficients can be obtained using Figure 7 [21]. The total force and bending moment acting at the top of the tower are mentioned in Table 4 [21].

\subsection{Structural analysis}

Structural analysis in this study is carried out utilizing finite element method approach, in which each segment is considered as a frame element. Due to the complexity of load distribution over the structure, it is simplified into a plain, manageable, uniform distribution over each segment. Following classical finite element method rules, nodal loads and nodal displacements of the structure can be obtained by which conducting all further steps, including stress analysis, becomes possible.

\section{Results and discussion}

Based on what has been mentioned so far, in this study, CBO, ECBO, and VPS algorithms are employed for investigation into optimal design of a simplified

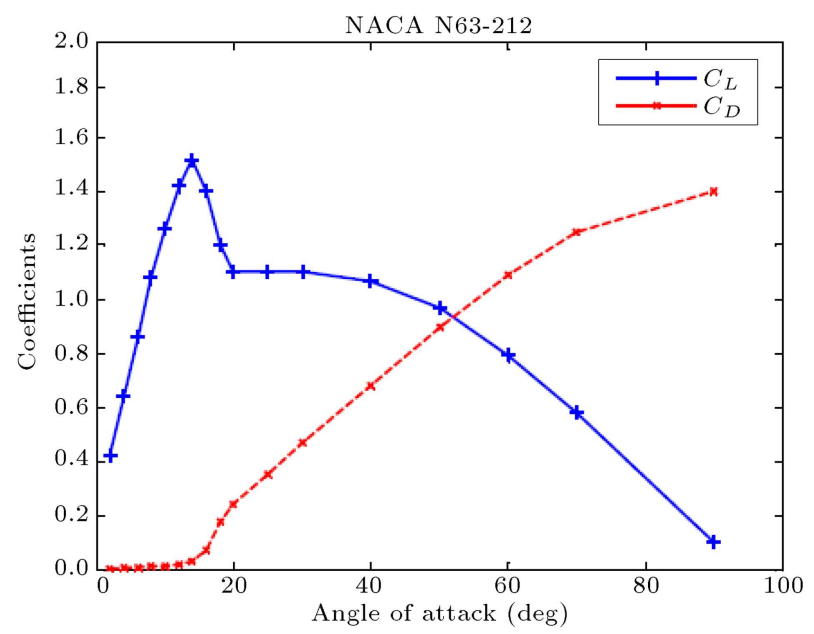

Figure 7. Drag and lift coefficients curves per angle of attack for the NACA N63-212 airfoil [20].

Table 4. Aerodynamic forces in the structure [21].

\begin{tabular}{cc}
\hline Total force $(\mathrm{kN})$ & 272.25 \\
Total moment (kN.m) & 18.14 \\
\hline
\end{tabular}

model of a monopile offshore wind turbine structure as a member of Horns Rev I offshore wind farm. This structure is firstly simplified into a manageable model, having 21 segments with predefined heights, which results in 42 design variables. Twenty Colliding Bodies in CBO and ECBO algorithms, and 20 particles in VPS algorithm are utilized for searching the possible minimum weight within the search spaces in a certain number of iterations (1000 iterations). The fundamental frequency of the structure is calculated using two different approaches. As the main approach, this value is obtained using a simplified $2 \mathrm{D}$ dynamic model, while an approximated formula is utilized as the second approach. The parameter $\varepsilon_{1}$ in the utilized penalty function is chosen as unity. In addition, $\varepsilon_{2}$ is selected 1.5 at the start, which linearly increases to 3 in the first approach and 10 in the second one. In this way, in early stages, an appropriate exploration may be conducted seeking better solutions and, as the optimization proceeds, unviable outcomes may be more strongly penalized. In ECBO algorithm, the parameter Pro is considered 0.3 when utilizing both approaches. However, in VPS algorithm, the values of $\alpha, p, w_{1}$, and $w_{2}$ are set to $0.15,80 \%, 0.3$, and 0.3 , respectively.

Nevertheless, lower bounds of diameter and thickness as the design variables are chosen as 0.5 and 0.01 $\mathrm{m}$, respectively, while 7 and $0.1 \mathrm{~m}$ are assumed as their upper bounds. Thirty-six different attempts, on aggregate, are made to search for optimal design of the structure using each of the meta-heuristic algorithms (i.e., CBO, ECBO, and VPS) and both dynamic analysis and approximated approach. Optimization results of all runs including the best weight and the corresponding design variables, averaged weight, design constraint values, and the rest of statistical indices, such as coefficient of variation, are provided in Tables 5 and 6 . The evolution processes of both cost function and merit function values that are obtained during optimization process are depicted in Figures 8 to 19 .

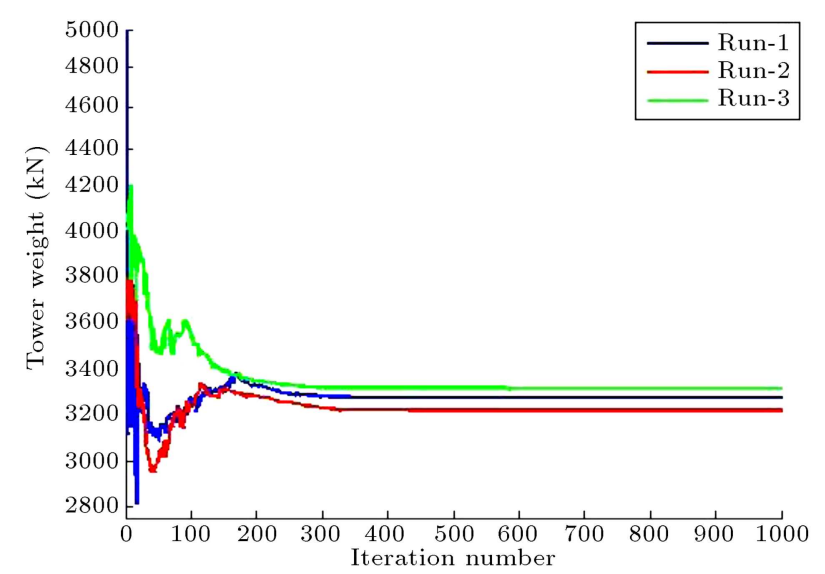

Figure 8. Convergence curves for cost function values using simplified dynamic model and CBO algorithm. 
Table 5. Optimum design variables using CBO, ECBO, and VPS algorithms.

\begin{tabular}{|c|c|c|c|c|c|c|}
\hline \multirow[b]{2}{*}{$\begin{array}{l}\text { Design } \\
\text { variable }\end{array}$} & \multicolumn{3}{|c|}{ Approximated formula } & \multicolumn{3}{|c|}{ Simplified dynamic model } \\
\hline & $\mathrm{CBO}(\mathrm{kN})$ & $\operatorname{ECBO}(\mathrm{kN})$ & VPS (kN) & $\mathrm{CBO}(\mathrm{kN})$ & $\operatorname{ECBO}(\mathrm{kN})$ & $\operatorname{VPS}(\mathbf{k N})$ \\
\hline$D_{1}$ & 6.5812 & 6.8043 & 6.6707 & 6.4373 & 6.6135 & 6.1930 \\
\hline$D_{2}$ & 6.2580 & 6.3149 & 6.0514 & 5.4484 & 6.4236 & 6.1178 \\
\hline$D_{3}$ & 5.9459 & 6.1511 & 6.0031 & 5.1879 & 6.3243 & 6.0869 \\
\hline$D_{4}$ & 5.8824 & 6.0840 & 6.0031 & 5.1344 & 5.9782 & 5.6298 \\
\hline$D_{5}$ & 5.8666 & 5.7786 & 5.9724 & 4.9109 & 4.7976 & 5.5594 \\
\hline$D_{6}$ & 5.8156 & 5.4006 & 5.8475 & 4.6055 & 4.5923 & 5.2562 \\
\hline$D_{7}$ & 4.8600 & 4.4278 & 4.4198 & 3.3093 & 3.1785 & 3.5138 \\
\hline$D_{8}$ & 3.0913 & 3.0354 & 3.1305 & 2.1844 & 2.4494 & 2.5775 \\
\hline$D_{9}$ & 2.9380 & 3.0033 & 3.0702 & 2.1457 & 2.3261 & 2.5311 \\
\hline$D_{10}$ & 2.9271 & 2.9923 & 2.9825 & 2.1454 & 2.2665 & 2.4968 \\
\hline$D_{11}$ & 2.8607 & 2.8135 & 2.8170 & 2.1317 & 2.2550 & 2.4967 \\
\hline$D_{12}$ & 2.8600 & 2.6252 & 2.6274 & 2.1297 & 2.2179 & 2.4880 \\
\hline$D_{13}$ & 2.7341 & 2.5393 & 2.5289 & 2.0739 & 2.1958 & 2.4095 \\
\hline$D_{14}$ & 2.5330 & 2.4245 & 2.4602 & 2.0682 & 2.1948 & 2.4014 \\
\hline$D_{15}$ & 2.3573 & 2.2731 & 2.2655 & 2.0627 & 2.1886 & 2.3848 \\
\hline$D_{16}$ & 1.8914 & 2.2238 & 2.2651 & 1.9804 & 2.1786 & 2.2970 \\
\hline$D_{17}$ & 1.5904 & 2.0965 & 1.9143 & 1.9538 & 2.1740 & 2.2826 \\
\hline$D_{18}$ & 1.5529 & 1.9928 & 1.9110 & 1.9520 & 2.1338 & 2.2369 \\
\hline$D_{19}$ & 1.5241 & 1.8116 & 1.8619 & 1.8485 & 2.0540 & 2.2205 \\
\hline$D_{20}$ & 1.4488 & 1.7737 & 1.7080 & 1.8045 & 2.0496 & 2.1805 \\
\hline$D_{21}$ & 1.3428 & 1.0931 & 1.2876 & 1.0922 & 2.0088 & 2.1800 \\
\hline$t_{1}$ & 0.0733 & 0.0756 & 0.0743 & 0.0846 & 0.0735 & 0.0689 \\
\hline$t_{2}$ & 0.0696 & 0.0702 & 0.0687 & 0.0846 & 0.0714 & 0.0680 \\
\hline$t_{3}$ & 0.0661 & 0.0684 & 0.0686 & 0.0792 & 0.0712 & 0.0679 \\
\hline$t_{4}$ & 0.0654 & 0.0677 & 0.0673 & 0.0787 & 0.0712 & 0.0678 \\
\hline$t_{5}$ & 0.0652 & 0.0642 & 0.0666 & 0.0775 & 0.0712 & 0.0677 \\
\hline$t_{6}$ & 0.0646 & 0.0600 & 0.0650 & 0.0771 & 0.0707 & 0.0669 \\
\hline$t_{7}$ & 0.0557 & 0.0579 & 0.0498 & 0.0771 & 0.0702 & 0.0668 \\
\hline$t_{8}$ & 0.0344 & 0.0337 & 0.0348 & 0.0754 & 0.0547 & 0.0395 \\
\hline$t_{9}$ & 0.0339 & 0.0334 & 0.0341 & 0.0705 & 0.0533 & 0.0394 \\
\hline$t_{10}$ & 0.0335 & 0.0333 & 0.0331 & 0.0669 & 0.0532 & 0.0394 \\
\hline$t_{11}$ & 0.0318 & 0.0324 & 0.0321 & 0.0648 & 0.0528 & 0.0394 \\
\hline$t_{12}$ & 0.0318 & 0.0299 & 0.0308 & 0.0518 & 0.0505 & 0.0394 \\
\hline$t_{13}$ & 0.0317 & 0.0298 & 0.0307 & 0.0518 & 0.0453 & 0.0392 \\
\hline$t_{14}$ & 0.0317 & 0.0278 & 0.0282 & 0.0515 & 0.0449 & 0.0392 \\
\hline$t_{15}$ & 0.0310 & 0.0268 & 0.0252 & 0.0508 & 0.0434 & 0.0392 \\
\hline$t_{16}$ & 0.0310 & 0.0248 & 0.0252 & 0.0508 & 0.0415 & 0.0390 \\
\hline$t_{17}$ & 0.0310 & 0.0234 & 0.0213 & 0.0505 & 0.0414 & 0.0368 \\
\hline$t_{18}$ & 0.0276 & 0.0229 & 0.0212 & 0.0491 & 0.0413 & 0.0368 \\
\hline$t_{19}$ & 0.0275 & 0.0217 & 0.0207 & 0.0490 & 0.0393 & 0.0364 \\
\hline$t_{20}$ & 0.0178 & 0.0198 & 0.0190 & 0.0483 & 0.0383 & 0.0364 \\
\hline$t_{21}$ & 0.0152 & 0.0122 & 0.0143 & 0.0463 & 0.0378 & 0.0364 \\
\hline Structure weight $(\mathrm{kN})$ & 2462.83 & 2411.40 & 2410.39 & 3218.63 & 2998.78 & 2783.19 \\
\hline Total weight (kN) & 3624.91 & 3573.48 & 3572.47 & 4380.71 & 4160.86 & 3945.27 \\
\hline Displacement (m) & 0.834999601672 & 0.834975732050 & 0.833430212601 & 0.832694519933 & 0.834994848834 & 0.832934385015 \\
\hline Frequency $(\mathrm{Hz})$ & 0.320000007028 & 0.320008499924 & 0.320000001757 & 0.539999999998 & 0.539991703292 & 0.539999993093 \\
\hline $\begin{array}{c}\text { Maximum stress ratio } \\
\text { (Combo1) }\end{array}$ & 0.52696 & 0.51149 & 0.52757 & 0.52984 & 0.53137 & 0.52948 \\
\hline $\begin{array}{c}\text { Maximum stress ratio } \\
(\text { Combo2) }\end{array}$ & 0.99944 & 0.96915 & 0.99735 & 0.99866 & 0.99985 & 0.99873 \\
\hline $\operatorname{Maximum}(D / t)$ & 89.99972 & 89.99732 & 89.99996 & 76.12561 & 89.99120 & 89.96153 \\
\hline Number of iterations & 1000 & 1000 & 1000 & 1000 & 1000 & 1000 \\
\hline
\end{tabular}

Table 6. Optimization outcomes in miscellaneous stages.

\begin{tabular}{ccccccc}
\hline & \multicolumn{3}{c}{ Approximated formula } & \multicolumn{3}{c}{ Simplified dynamic model } \\
\cline { 2 - 6 } & CBO (kN) & ECBO (kN) & VPS (kN) & CBO (kN) & ECBO (kN) & VPS (kN) \\
\hline Run-1 & 2603.05 & 2501.84 & 2430.65 & 3273.08 & 3040.71 & 2783.19 \\
Run-2 & 2605.49 & 2431.54 & 2410.39 & 3218.63 & 3324.23 & 2938.06 \\
Run-3 & 2462.83 & 2411.40 & 2426.14 & 3315.75 & 2998.78 & 3014.58 \\
Best weight (kN) & 2462.83 & 2411.40 & 2410.39 & 3218.63 & 2998.78 & 2783.19 \\
Averaged weight (kN) & 2557.12 & 2448.26 & 2422.40 & 3269.15 & 3121.24 & 2911.94 \\
Standard deviation (kN) & 66.68 & 38.77 & 8.68 & 39.75 & 144.55 \\
Coefficient of variation (\%) & 2.61 & 1.58 & 0.36 & 1.22 & 46.25 \\
\hline
\end{tabular}




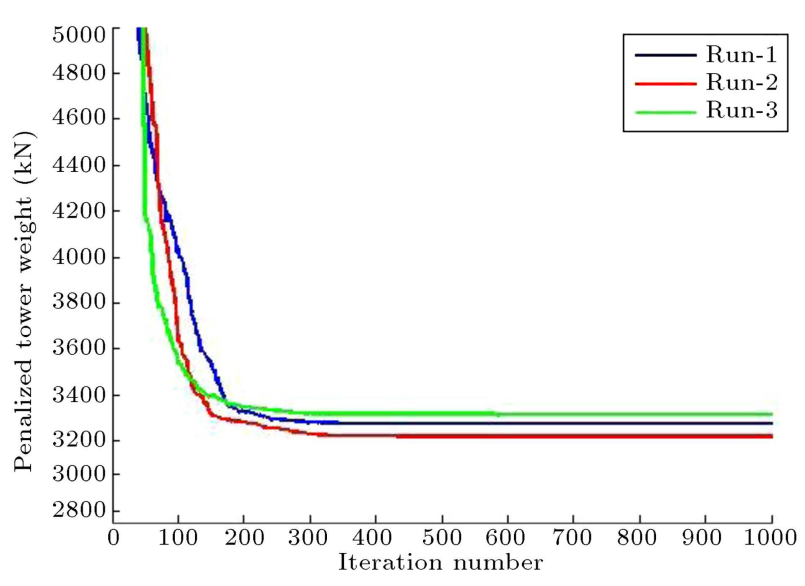

Figure 9. Convergence curves for merit function values using simplified dynamic model and CBO algorithm.

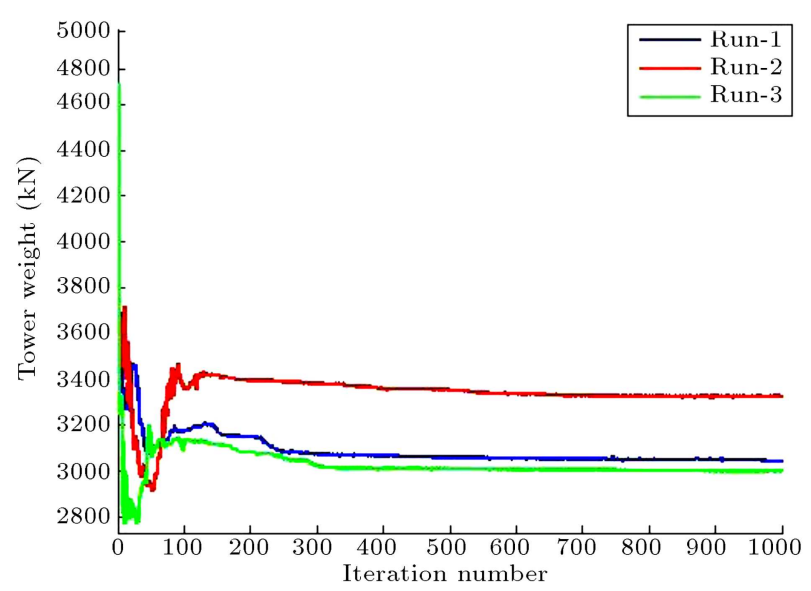

Figure 10. Convergence curves for cost function values using simplified dynamic model and ECBO algorithm.

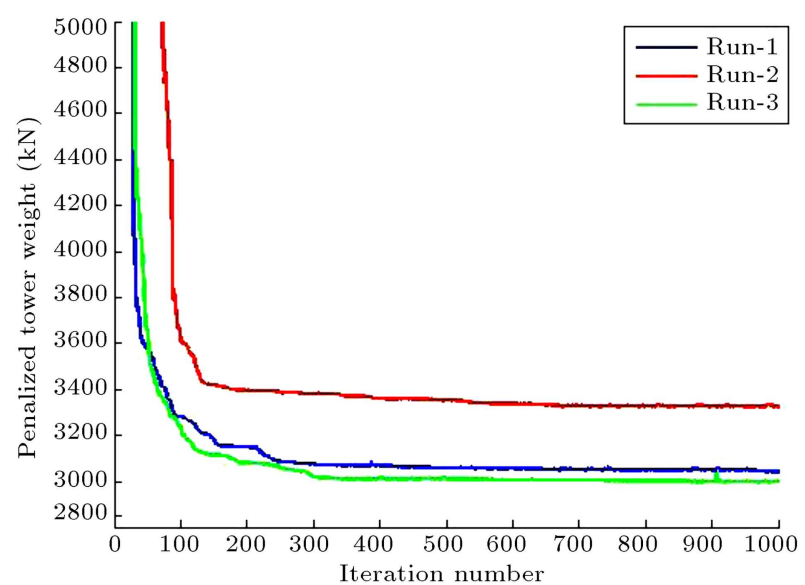

Figure 11. Convergence curves for merit function values using simplified dynamic model and ECBO algorithm.

As noticed, none of the constraints, including the frequency constraint, is infringed during optimization.

\section{Concluding remarks}

The very first fact that should be noted is that

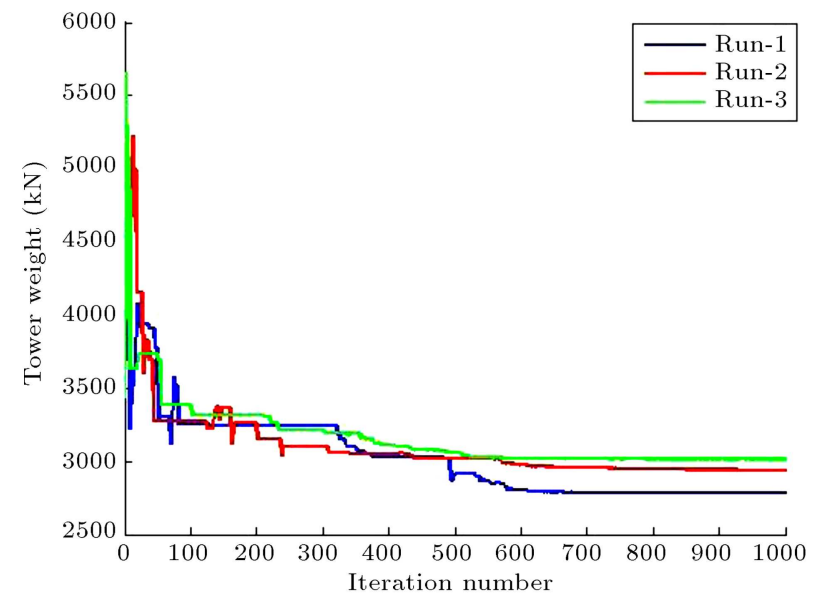

Figure 12. Convergence curves for cost function values using simplified dynamic model and VPS algorithm.

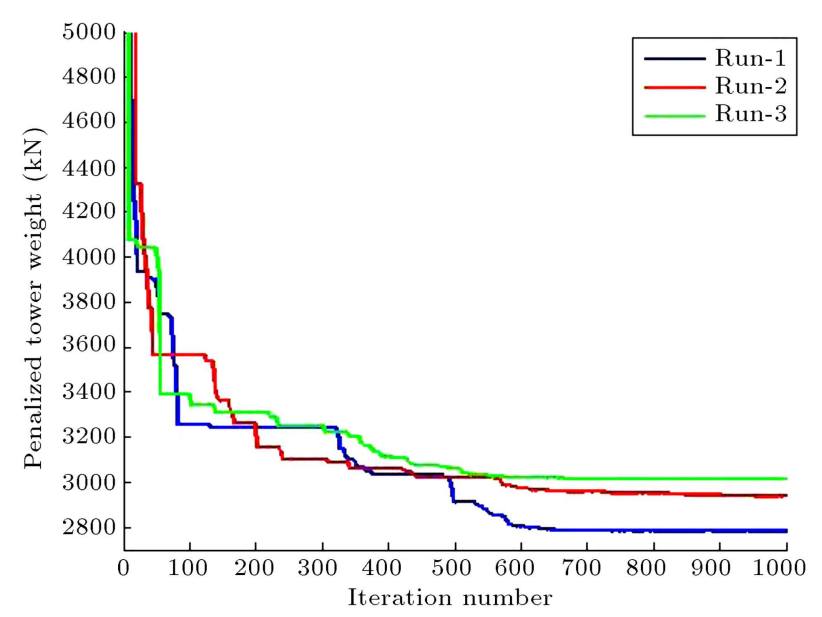

Figure 13. Convergence curves for merit function values using simplified dynamic model and VPS algorithm.

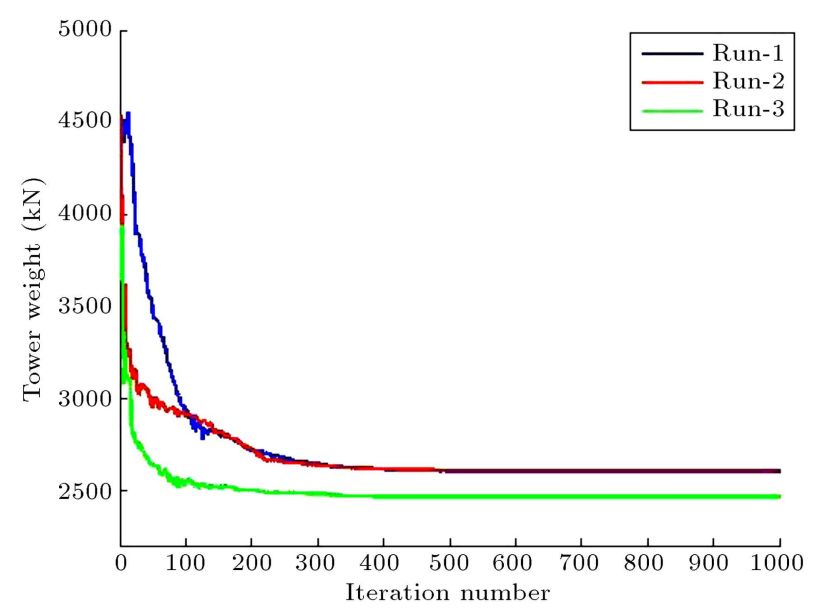

Figure 14. Convergence curves for cost function using approximated formula and CBO algorithm.

structural optimization of offshore structures and, more specifically, offshore wind turbine structures is a tedious and troublesome mission due to the nonconvexity and non-linearity of the problem, coming 


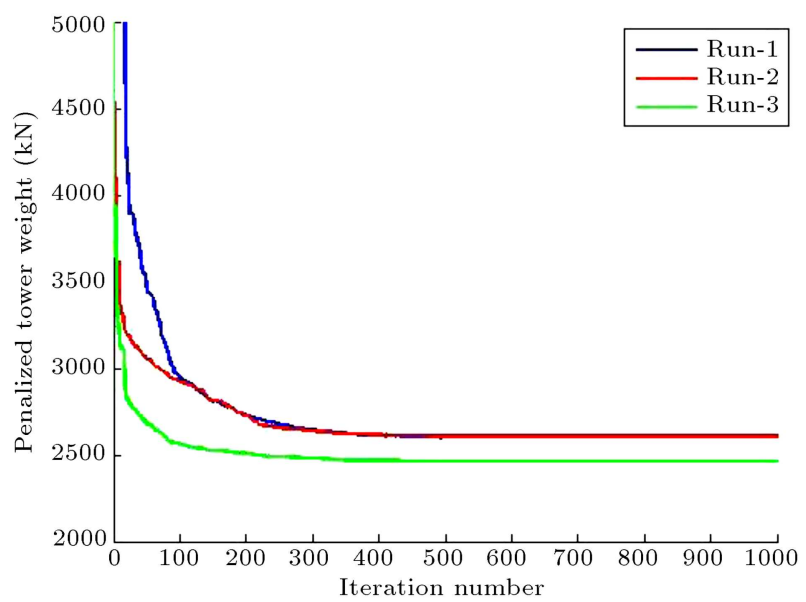

Figure 15. Convergence curves for merit function values using approximated formula and CBO algorithm.

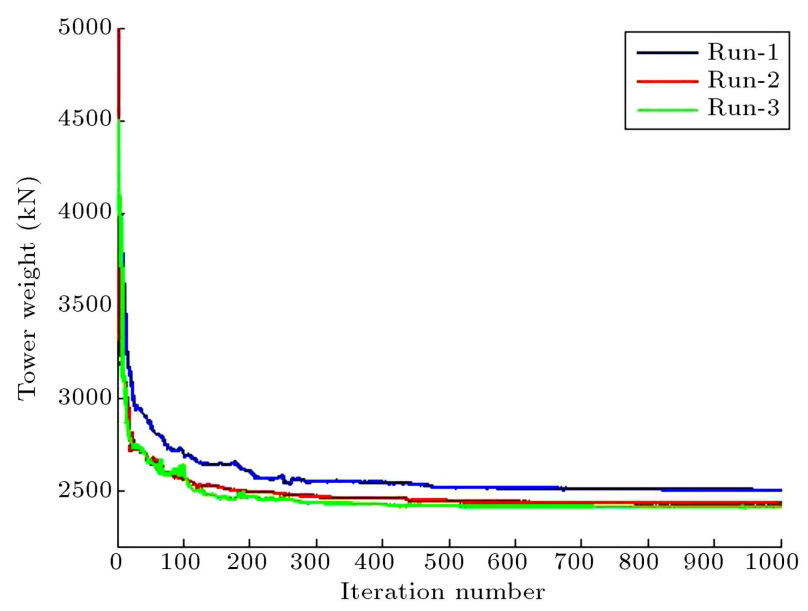

Figure 16. Convergence curves for cost function using approximated formula and ECBO algorithm.

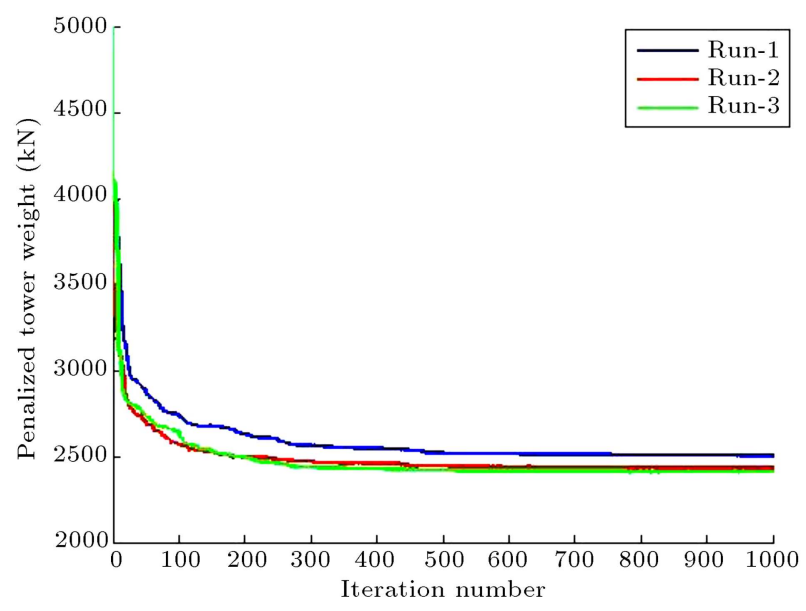

Figure 17. Convergence curves for merit function values using approximated formula and ECBO algorithm.

from the simultaneous alterations in applied loads with changes in the cross-sections of the structure. Comparing the outcomes of this study with the total weight of the structure reported in [21], which is carried

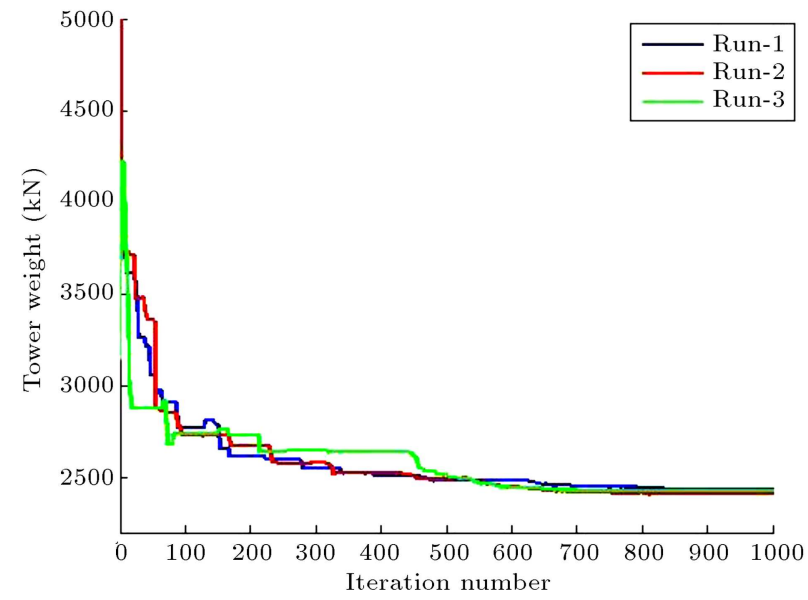

Figure 18. Convergence curves for cost function using approximated formula and VPS algorithm.

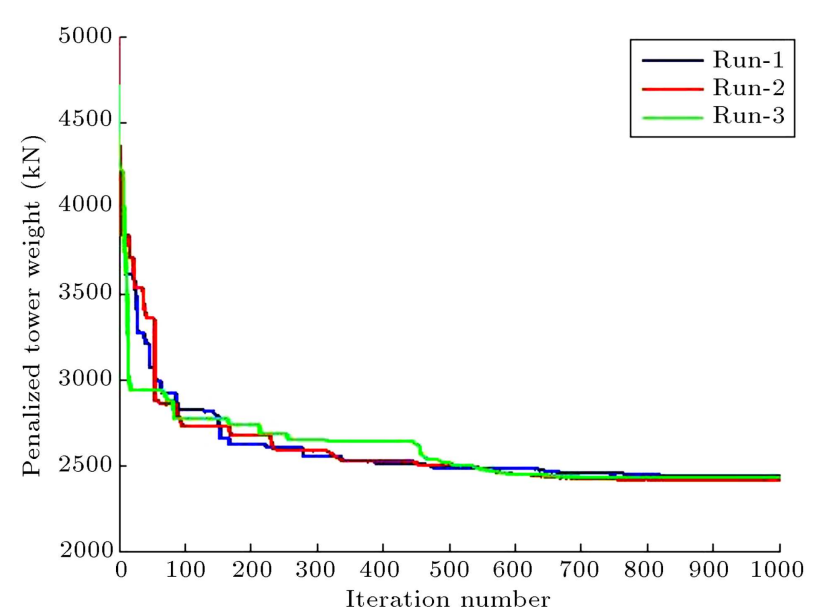

Figure 19. Convergence curves for merit function values using approximated formula and VPS algorithm.

out based on the same assumptions as those of this study, it can be noticed that the total weight of the structure is remarkably decreased while all the desired constraints are fulfilled.

The fundamental frequency of the structure was calculated using two miscellaneous approaches. As the first one, the entire structure was simplified into a simplified 2D dynamic model in which each segment was considered as a frame element with consistent mass. Each node of these elements contained 3 degrees of freedom: one horizontal translation, one vertical translation, and one planar rotation. As the other approach, an approximated model that resembled the whole structure with a cantilever beam was utilized. The differences between results could be justified by noting how the stiffness matrix was calculated. In the first approach, the stiffness matrix of the structure was obtained by assembling stiffness matrix of each segment when considering them as a frame element. Nevertheless, the stiffness of the structure in the second approach was gained using averaged diameter and 
thickness. As a result, the fundamental frequency of the structure when using the first approach was accomplished near the upper bound of the desired interval, while utilization of the second approach resulted in frequencies in the vicinity of the lower bound of the interval. Additionally, as expected, the obtained results attested to the superiority and efficiency of VPS over $\mathrm{CBO}$ and ECBO. In addition, refereeing to the results, ECBO worked more properly than CBO in this optimization problem.

In summary, optimal design of a simplified monopile offshore wind turbine structure by using Colliding Bodies Optimization (CBO) algorithm, Enhanced Colliding Bodies (ECBO) algorithm, and Vibrating Particle System (VPS) algorithm was presented in this study. CBO was developed based on simulating behavior of bodies when colliding with each other. Parameter independency and noticeable simplicity in implementation can be stated as its two main features. Using a memory in order to improve the CBO performance, ECBO also enjoys a mechanism that results in good escape from trapping in local minima in comparison with CBO. VPS algorithm, which involved a number of candidate solutions representing the particle system, was developed based on the free vibration of the single degree of freedom systems. Having total weight of the structure and cross-section sizes defined as the objective function and design variables, respectively, optimization process was conducted attempting to minimize the objective function while meeting all design constraints. The fundamental frequency of the structure was calculated using two miscellaneous approaches, namely 2D dynamic model of the structure and an approximated formula. The former obviously resulted in upshots that were more pragmatic. The efficiency and applicability of the proposed model were then appraised based on a design example from Horns Rev I offshore wind farm. Comparison between the outcomes reported in [21] and the results of this research, remarkable weight reduction was observed while satisfying all constraints, which attested to proficiency of the utilized algorithms.

\section{References}

1. Lynn, Paul A., Onshore and Offshore Wind Energy: An Introduction, John Wiley and Sons (2011).

2. Karimirad, M., Offshore Energy Structures: for Wind Power, Wave Energy and Hybrid Marine Platforms, Springer (2014).

3. Muskulus, M. and Schafhirt, S. "Design optimization of wind turbine support structures - a review", $J$. Ocean Wind Ener., 1(1), pp. 12-22 (2014).

4. Kaveh, A., Advances in Metaheuristic Algorithms for Optimal Design of Structures, Second edition, Springer International Publishing, Switzerland (2017).
5. Kaveh, A. and Mahdavi, V.R., Colliding Bodies Optimization: Extensions and Applications, Springer International Publishing, Switzerland (2015).

6. Kaveh, A. and Talatahari, S. "A novel heuristic optimization method: charged system search", Acta Mech., 213(3), pp. 267-289 (2010)

7. Kaveh, A. and Ilchi Ghazaan, M. "A new metaheuristic algorithm: vibrating particles system", Sci. Iran., Transactions A, Civil Engineering, 24(2), pp. 551-566 (2017).

8. Gholizadeh, S. and Seyedpoor, S.M. "Shape optimization of arch dams by metaheuristics and neural networks for frequency constraints", Sci. Iran., Transactions A, Civil Engineering, 18(5), pp. 1020-1027 (2011).

9. Gholizadeh, S. and Shahrezaei, A.M. "Optimal placement of steel plate shear walls for steel frames by bat algorithm", Struct Des. Tall Special Build., 24(1), pp. $1-18$ (2015).

10. Kaveh, A., Applications of Metaheuristic Optimization Algorithms in Civil Engineering, Springer Verlag. Switzerland (2017).

11. Kaveh, A., Ghafari, M.H., and Gholipour, Y. "Optimum seismic design of steel frames considering the connection types", J. Construct. Steel Res., 130, pp. 79-87 (2017).

12. Kaveh, A. and Nasrollahi, A. "A hybrid charged system search and particle swarm optimization for optimal design of engineering structures", Sci. Iran., Transactions A, Civil Engineering, 21(2), pp. 295-305 (2014).

13. Kaveh, A. and Javadi, S.M. "Shape and size optimization of trusses with multiple frequency constraints using harmony search and ray optimizer for enhancing the particle swarm optimization algorithm", Acta Mech., 225(6), pp. 1595-1605 (2014).

14. Kaveh, A. and Rezaie, M. "Topology and geometry optimization of single layer domes utilizing colliding bodies optimization", Sci. Iran., Transactions A, Civil Engineering, 23(2), pp. 535-547 (2016).

15. Kaveh, A., Mahdavi, V.R., and Kamalinejad, M. "Optimal design of the monopole structures using CBO and ECBO algorithms", Period. Polytech. - Civil Eng. Trans., 61(1), pp. 110-116 (2017).

16. Kaveh, A. and Ilchi Ghazaan, M. "Enhanced colliding bodies algorithm for truss optimization with frequency constraints", J. Comput. Civil Eng., 29(6) (Nov. 2015).

17. Thiry, A., Rigo, P., Buldgen, L., Raboni, G., and Bair, F. "Optimization of monopile offshore wind structures", Advances in Marine Structures, pp. 633642 (2011).

18. Veritas, D.N. "Design of offshore wind turbine structures", Offshore Standard, DNV-OS-J101 (2014).

19. Veritas, D.N. "Design and manufacture of wind turbine blades, offshore and onshore wind turbines", $D N V$ Standard, DNV-DS-J102 (2010). 
20. Tempel, J. van der "Design of support structures for offshore wind turbines", PhD. Thesis, Delft University of Technology, Section Offshore Engineering (2006).

21. Leite, O.B. "Review of design procedures for monopile offshore wind structures", Master Thesis, University of Porto (2015).

22. Bhattacharya, S., Cox, J.A., Lombardi, D., and Wood, D.M. "Dynamic of offshore wind turbines supported on two foundations-article", Geotech. Eng., 166, pp. 159169 (2013).

23. Quilligan, A., O'Connor, A., and Pakrashi, V. "Fragility analysis of steel and concrete wind turbine towers", Eng. Struct., 36, pp. 270-282 (2012).

24. Hartog J.P.D., Recent Technical Manifestations of Von Karman's Vortex Wake, Massachusetts Institute of Technology, Department of Mechanical Engineering (1953).

25. Eurocode 3: "Design of steel structures - Part 11: General rules and rules for buildings", European Committee for Standardization (2010).

\section{Biographies}

Ali Kaveh was born in 1948 in Tabriz, Iran. After graduation from the Department of Civil Engineering at the University of Tabriz in 1969, he continued his studies on Structures at Imperial College of Science and Technology at London University, and received his MSc, DIC, and PhD degrees in 1970 and 1974, respectively. He then joined the Iran University of Science and Technology. Professor Kaveh is the author of 565 papers published in international journals and 145 papers presented at national and international conferences. He has authored 23 books in Persian and 8 books in English published by Wiley, Research Studies Press, American Mechanical Society, and Springer.

Sepehr Sabeti was born in Tehran, Iran, in 1992. He is currently an MSc student in the field of Coastal, Ports, and Marine Structures Engineering at Iran University of Science and Technology (IUST). His main research interests are structural optimization and dynamic analysis of offshore wind turbine structures. 